\title{
Plectasin has antibacterial activity and no affect on cell viability or IL-8 production
}

\author{
Shintaro Hara ${ }^{\dagger}$, Hiroshi Mukae ${ }^{\dagger *}$, Noriho Sakamoto ${ }^{\dagger}$, Hiroshi Ishimoto ${ }^{\dagger}$, \\ Misato Amenomori ${ }^{\dagger}$, Hanako Fujita ${ }^{\dagger}$, Yuji Ishimatsu ${ }^{\dagger}$, Katsunori Yanagihara ${ }^{\S}$, and \\ Shigeru Kohno ${ }^{\dagger}$
}

${ }^{\dagger}$ Second Department of Internal Medicine and ${ }^{\S}$ Department of Laboratory Medicine, Nagasaki University School of Medicine, 1-7-1 Sakamoto, Nagasaki 852-8501, Japan

\section{KEYWORDS}

plectasin, human defensins, antibacterial activity, cytokine induction, cytotoxicity

*Corresponding author: Hiroshi Mukae

Second Department of Internal Medicine, Nagasaki University School of Medicine, 1-7-1 Sakamoto, Nagasaki 852-8501, Japan

Tel: $\quad+81-95-819-7273 \quad$ Fax: $\quad+81-95-849-7285 ; \quad$ E-mail address: hmukae@net.nagasaki-u.ac.jp 


\section{Abstract}

Animals and plants express endogenous peptide antibiotics called defensins. Defensins show broad-spectrum antimicrobial activity, even against bacteria that have resistance to conventional antibiotics, which has made them viable candidates for new antibiotics. However, human defensins have failed to reach the market because of their cytotoxic effects and non-antimicrobial bioactivities. Plectasin is a defensin that has shown promise but has not had its potentially negative effects clarified. To address this issue, we examined plectasin's cytotoxicity in human cells using an AlamarBlue reduction assay, its interleukin (IL)-8-inducing capacity using real-time PCR and ELISA, and measured its MIC against bacteria. We confirmed that plectasin has specific antibacterial activity against S. pneumoniae. Plectasin showed no cytotoxicity to A549 cells, normal human bronchial epithelial cells, or lung fibroblasts, and it did not induce IL-8 transcription or production in A549 cells. Our results suggest that plectasin could be an inoffensive alternative antibiotic for clinical application.

Keywords; plectasin; defensin; human neutrophil peptide-1; antibacterial activity; cytotoxicity; interleukin-8 induction; A549 cell; normal human bronchial epithelial cell; normal human lung fibroblast 


\section{Introduction}

Human airways are protected from invading microorganisms by a highly efficient innate immune system. Bronchial epithelial fluid contains various intrinsic antimicrobial peptides, such as lysozyme, lactoferrin, secretory phospholipase-A2, and defensins, which represent essential components of the innate immune system. Antimicrobial peptides, including defensins, are produced in many organisms including bacteria, insects, plants, and vertebrates. The defensins contain a conserved cysteine-stabilized $\alpha$-helix and $\beta$-sheet structural motif, and human defensins have broad-spectrum antimicrobial activity against Gram-positive and Gram-negative bacteria, fungi, protozoa, and enveloped viruses [1]. Human defensins also display marked in vivo antibacterial activity against experimental infections including Klebsiella pneumoniae and Mycobacterium tuberculosis in mice [2, 3]. Therefore, defensins have emerged as promising agents, especially against antibiotic-resistant pathogens [4]. Despite the high potential of human defensins as antimicrobial drugs, there are some barriers to their development for clinical application, particularly for systemic use [5]. The antibacterial activity of defensins is generally ascribed their ability to disrupt membrane integrity and function, which ultimately leads to lysis of the microorganism. Being positively charged, defensins interact with negatively charged components of microbial membranes that include lipopolysaccharides of Gram-negative bacteria or lipoteichoic acid of Gram-positive bacteria [6, 7]. As human defensins are strong cationic peptides, they display a significant reduction in their antibacterial 
potency in the presence of complex fluids such as plasma, serum, saliva, and sputum [5, $8,9]$. In addition, high concentrations of human defensins reduce the viability of human cells [10-12]. Human $\alpha$-defensins have also been reported to be associated with acute respiratory distress syndrome and pulmonary fibrosis [12-15]. Furthermore, human defensins, especially $\alpha$-defensins, induce the synthesis of inflammatory cytokines in endothelial and epithelial cells $[11,16]$, which may result in an inexpedient inflammatory response, particularly during an infection. Although the toxicology and pharmacokinetics of human defensins have not been clarified, these characteristics of human defensins could be disadvantageous for their clinical application as antimicrobial agents.

Recently, defensin-like peptides have also been found in many kinds of organisms, such as plants, insects [17], and fungi [18]. Plectasin is the first defensin-like peptide to be isolated from a fungus, the saprophytic ascomycete reported by Mygind and colleagues [19]. Recombinant plectasin is especially active against Streptococcus pneumoniae, including strains resistant to conventional antibiotics. Plectasin also cured mice of experimental peritonitis and pneumonia caused by $S$. pneumoniae as efficaciously as vancomycin and penicillin [19]. These findings showed that plectasin has properties that make it an attractive candidate for development into a human therapeutic agent. However, no report is available on the cytotoxicity of this peptide for human cells, and the induction of inflammatory cytokines by plectasin in human lung epithelial cells has not been studied. Furthermore, no report is available on the 
bioactivity of synthetic (as opposed to recombinant) plectasin.

To confirm whether plectasin is clinically valuable as an antibiotic, we evaluated the effects of synthetic plectasin on human lung cells, including cytotoxicity and induction of inflammatory cytokines, in addition to measuring its MIC against bacteria.

\section{Materials and Methods}

Reagents. Synthetic plectasin and human neutrophil peptide (HNP)-1, one of the human defensins, were purchased from Peptide Institute, Inc. (Osaka, Japan). Plectasin and HNP-1 were dissolved in saline yielding stock solutions and subsequently diluted to appropriate concentrations in broth for antimicrobial assays or in medium for cytokine assays.

Antimicrobial assay. The following bacteria were tested: penicillin-susceptible Streptococcus pneumoniae (PSSP) ATCC 49619 and 11 clinical isolates, 14 clinical isolates of penicillin-resistant Streptococcus pneumoniae (PRSP), methicillin-susceptible Staphylococcus aureus (MSSA) ATCC 29213 and 10 clinical isolates, 11 clinical isolates of methicillin-resistant Staphylococcus aureus (MRSA), 10 clinical isolates of susceptible coagulase-negative Staphylococci (SCNS), 10 clinical isolates of resistant coagulase-negative Staphylococci (RCNS), 10 clinical isolates of Haemophilus influenzae, and three clinical isolates of Pseudomonas aeruginosa. All 
strains of clinical isolates were isolated in Nagasaki University Hospital (Nagasaki, Japan). S. pneumoniae were grown on blood agar plate and $H$. influenzae on chocolate agar. Other bacteria were grown on Mueller-Hinton II agar (MH II; Becton Dickinson, Franklin Lakes, NJ, USA). Two clinical isolates of Candida glabrata and two clinical isolates of Cryptococcus neoformans were also tested. Fungal strains were grown on yeast extract peptone glucose (YPD; Becton Dickinson) agar plates.

The minimum inhibitory concentration (MIC) was determined using a microbroth dilution method with MH II broth for bacterial species or YPD broth for fungal species with the final inoculum concentration of approximately $1 \times 10^{5} \mathrm{CFU} / \mathrm{ml}$, according to the procedures outlined by the Clinical and Laboratory Standards Institute (CLSI) [20]. The Broth was supplemented with 2 - 5\% Strepto-Haemo supplement (EIKEN chemical, Tokyo, Japan) for all $S$. pneumoniae and $H$. influenzae. The diluted bacterial suspensions were added to wells containing two-fold plectasin dilutions. The MIC was taken as the lowest plectasin concentration at which observable growth was inhibited. Experiments were performed in duplicate. In order to clarify that human bodily fluid did not inhibit the antibacterial activity of plectasin, suspensions of S. pneumoniae (PSSP and PRSP) were exposed to different concentrations of plectasin in MH II broth alone or containing $3 \%$ or $10 \%$ human serum obtained from healthy volunteers. S. aureus and P. aeruginosa were incubated for 16 - $20 \mathrm{~h}$; S. pneumoniae and $H$. influenzae for $24 \mathrm{~h}$ at $37^{\circ} \mathrm{C}$ in ambient air in polystyrene 96 -well round-bottomed plates (IWAKI, Japan); and C. glabrata for $48 \mathrm{~h}$ and C. neoformans for $72 \mathrm{~h}$ at $35^{\circ} \mathrm{C}$ in $5 \% \mathrm{CO}_{2}$. 
Cell culture. Human alveolar epithelial cell line A549 cells were purchased from the American Type Culture Collection (Manassas, VA, USA) and grown as monolayers in tissue culture flasks (BD Falcon ${ }^{\mathrm{TM}}$, Franklin Lakes, NJ, USA) at $37^{\circ} \mathrm{C}$ in a $5 \%$ $\mathrm{CO}_{2}$-humidified atmosphere. The cells were maintained in Dulbecco's modified minimal essential medium (DMEM) supplemented with $10 \%$ heat-inactivated fetal bovine serum (FBS; Invitrogen, Carlsbad, CA, USA). The cells were passaged weekly after exposure to $0.25 \%(\mathrm{w} / \mathrm{v})$ trypsin. Subconfluent A549 monolayers $\left(5.0 \times 10^{5}\right.$ cells $)$ were grown in 60-mm dishes in DMEM without FBS for $24 \mathrm{~h}$ before starting experiments. Normal human bronchial epithelial cells (NHBE; Lonza, Basel, Switzerland) or normal human lung fibroblasts (NHLF; Lonza) obtained from three different donors were grown in tissue culture flasks in a humidified incubator. NHBE were maintained in bronchial epithelial growth media (Lonza), whereas NHLF were grown in fibroblast growth media (Lonza). All experiments were performed at either the third or the fourth passage. The cell number was counted with a hemocytometer.

AlamarBlue reduction assay. Confluent cells were plated in 96-well tissue culture plate (BD) at a concentration of $1 \times 10^{4}$ cells/well. Cells were incubated with medium alone (control) or $1.0-50 \mu \mathrm{g} / \mathrm{ml}$ of plectasin or HNP-1 for $24 \mathrm{~h}$. Then the cells were treated for $3 \mathrm{~h}$ with 10-fold diluted AlamarBlue (Serotec, Oxford, UK) with medium. Cell viability, as indicated by the reducing environment of proliferating cells, was measured 
at $540 \mathrm{~nm}$ excitation and $620 \mathrm{~nm}$ emission. Cell viability is reported as \% of control.

Real-Time PCR. For the analysis of IL-8 mRNA expression, A549 cells grown to subconfluence $\left(5.0 \times 10^{5} / \mathrm{dish}\right)$ in $60-\mathrm{mm}$ cell culture dishes were incubated for $3 \mathrm{~h}$ with culture medium alone (control) or $1.0-50 \mu \mathrm{g} / \mathrm{ml}$ of plectasin or HNP-1. Total RNAs were isolated from cultured A549 cells using an RNeasy Plus Mini Kit (QIAGEN, Hilden, Germany) following manufacturer's recommendations. A volume of $1 \mu \mathrm{l}$ of pooled RNA was reverse-transcribed in a total reaction volume of $20 \mu$ containing 0.5 $\mu \mathrm{g}$ random hexamer primer, 20 units RNasin ribonuclease inhibitor, and SuperScript III First-Strand Synthesis System (Invitrogen) according to the supplier's instructions. The resulting cDNA was subjected to quantitative real-time polymerase chain reaction (QRT-PCR). The QRT-PCR amplification was performed using the TaqMan Gene Expression Assays set for IL-8 gene and human beta-actin for the endogenous control (Applied Biosystems, Foster City, CA, USA) in combination with the TaqMan Universal PCR Master Mix (Applied Biosystems). Cycle to cycle fluorescence emission readings were monitored and analyzed by ABI PRISM 7700 Sequence Detection System (Applied Biosystems). Quantitation of IL-8 mRNA expression was calculated using the comparative $\mathrm{C}_{\mathrm{T}}$ method.

Enzyme-linked immunosorbent assay (ELISA). For the analysis of IL-8 production, A549 cells grown to subconfluence $\left(5.0 \times 10^{5} /\right.$ dish $)$ in $60-\mathrm{mm}$ dishes were incubated 
for $24 \mathrm{~h}$ with culture medium alone (control) or $1.0-50 \mu \mathrm{g} / \mathrm{ml}$ of plectasin or HNP-1. Cell free supernatants were recovered by centrifugation and stored at $-80^{\circ} \mathrm{C}$ until they were assayed. IL-8 levels were measured using a Quantikine human CXCL8/IL-8 ELISA kit according to the supplier's instructions (R\&D Systems Inc., Minneapolis, MN, USA).

Statistical analysis. Results were analyzed by Student's t test for comparison between two groups and by non parametric equivalents of analysis of variance (ANOVA) for multiple comparison. Significance was assumed at $\mathrm{p}<0.05$. 


\section{Results}

MIC determination

To confirm that synthesized plectasin has an inhibitory effect against several species of Gram-positive bacteria [19], an antimicrobial assay was performed first. As shown in Table 1, growth of $S$. pneumoniae was markedly inhibited, suggesting that synthesized plectasin is a biologically active agent. Gram-negative bacteria, including $H$. influenzae and $P$. aeruginosa, were considerably more resistant to plectasin. The fungi C. glabrata and C. neoformans were resistant to plectasin (data not shown). Figure 1 shows that plectasin had the same MIC in the absence or presence of $3-10 \%$ human serum. The MICs against PSSP and PRSP were $2 \mu \mathrm{g} / \mathrm{ml}$ and $0.25 \mu \mathrm{g} / \mathrm{ml}$, respectively.

Cytotoxicity of plectasin on human bronchial epithelial cells

Cell viabilities of A549 cells, NHBE, and NHLF were not affected by plectasin, as shown in Fig. 2. In contrast, $10 \mu \mathrm{g} / \mathrm{ml} \mathrm{HNP-1} \mathrm{induced} \mathrm{cell} \mathrm{proliferation} \mathrm{of} \mathrm{A549} \mathrm{by}$ $7.9 \%$ and NHBE by $13.6 \%$, and $5 \mu \mathrm{g} / \mathrm{ml} \mathrm{HNP}-1$ induced cell proliferation of NHLF by 9.3\%. Importantly, $50 \mu \mathrm{g} / \mathrm{ml} \mathrm{HNP}-1$ significantly reduced the viability of A549 by $54.3 \%$, NHBE by $71.6 \%$, and NHLF by $37.6 \%$ compared with control.

Effect of plectasin on IL-8 mRNA expression and protein production

mRNA expression of IL-8 in A549 cells was not elicited by plectasin (Fig. 3A). In contrast to plectasin, IL-8 mRNA expression in A549 cells treated with HNP-1 
significantly increased in a dose-dependent manner (Fig. 3A). Plectasin did not affect IL-8 protein secretion from A549 cells compared with medium alone (Fig. 3B). However, IL-8 protein secretion in A549 cells treated with HNP-1 significantly increased in a dose-dependent manner (Fig. 3B). 


\section{Discussion}

The major findings of the present study are that synthesized plectasin has antimicrobial activities against Gram-positive bacteria, especially S. pneumoniae, including strains resistant to conventional antibiotics and without cytotoxic effects on human A549 cells, NHBE, or NHLF. In addition, this agent did not induce IL-8 in A549 cells. These effects are apparently different from human defensins and the results indicate that plectasin offers promise as a new antibiotic against Gram-positive bacteria without side effects for systemic use.

First, we examined the antibacterial activity of purchased synthetic plectasin and observed almost the same activity, especially for S. pneumoniae, as reported by Mygind et al [19]. This shows that plectasin can be synthesized, and fully processed active plectasin can be effectively produced at high yields. Human defensin molecules are strongly cationic and act by binding to cellular membranes and directly perturbing membrane function [21]. A number of studies have demonstrated the ability of salts, in the form of $\mathrm{NaCl}$, to inhibit the activity of defensin to various extents $[22,23]$. In addition, human defensin requires low ionic strength and is deactivated by human serum components [5, 9]. We ascertained that HNP-1 did not show antibacterial activity against S. pneumoniae, S. aureus, or P. aeruginos in MH II broth, which contained beef extract, acid hydrolysate of casein, starch, $20-25 \mathrm{mg} / \mathrm{l}$ calcium, and $10-12.5 \mathrm{mg} / \mathrm{l}$ magnesium, at indicated $\mathrm{pH} 7.3 \pm 0.1$. [24]. As in traditional reports, MIC measurements of HNP-1 and other human defensins are required to be tested by radial 
diffusion assay [25] or colony count assay [26]. Meanwhile, we showed that plectasin was bactericidal in MH II broth by the procedure of CLSI [20]. This suggests that plectasin is stable against negatively-charged proteins and cations. In addition, we measured the MIC of plectasin against S. pneumoniae with human serum. Regardless of the presence of human serum, the results showed the same MICs against the same strains, which showed that the bactericidal activity of plectasin was not deactivated by human serum. These findings suggest that plectasin has advantages for systemic use, because it is considered stable under physiological conditions. In addition, the MIC and minimum bactericidal concentration of plectasin were almost the same. This property suggests that plectasin has altered the bacterial growth, an irreversible process leading to death within seconds to minutes of exposure [19]. Although the mechanism by which plectasin kills or inactivates bacteria is not fully understood, it is not a cationic protein and may act against bacteria by means different than those of other defensins. In this context, plectasin did not have antimicrobial activity against fungi and Gram-negative bacteria, including $P$. aeruginosa and $H$. influenzae, which are leading causes of lung infections. Thus, plectasin has a very narrow spectrum which is different from human defensins. Further studies are needed to clarify the exact mechanisms.

Second, we demonstrated that cell viabilities of A549 cells, NHBE, and NHFL were not affected by plectasin, which indicates that it has no clinically significant cytotoxicity against human bronchial and lung cells. In contrast, HNP-1 at more than $50 \mu \mathrm{g} / \mathrm{ml}$ significantly induced cell lysis $[10-12,16]$. We have previously reported that $24 \mathrm{~h}$ 
treatment with $>20 \mu \mathrm{g} / \mathrm{ml}$ of HNP-1 and $>50 \mu \mathrm{g} / \mathrm{ml}$ of human $\beta$ defensin-2 was cytotoxic to NHBE [11], and $24 \mathrm{~h}$ treatment with $>50 \mu \mathrm{g} / \mathrm{ml}$ of HNP-1 was cytotoxic to NHLF [12]. Though Mygind and colleagues have reported that plectasin was neither cytotoxic for murine fibroblasts or human epidermal keratinocytes, nor hemolytic for human erythrocytes [19], this is the first study to examine the cytotoxicity of plectasin to human lung cells. We also demonstrated that plectasin did not induce cell proliferation while HNP-1 induces lung epithelial cell proliferation [27]. Our results indicate that plectasin could be used safely for humans, even if high doses might be necessary against gram-positive bacteria, which are more resistant to plectasin than $S$. pneumoniae.

Finally, plectasin did not induce mRNA expression and protein production of IL-8 in A549 cells, whereas HNP-1 induces inflammatory cytokines from lung epithelial cells $[11,16]$. IL-8 is one of the potent chemokines that are important in airway neutrophilic inflammation. IL-8 is produced by alveolar macrophages as well as by a number of non-inflammatory cells [28]. Increased levels of IL-8 in airway lining fluids have been reported in several airway inflammatory diseases, in which they were decreased by successful therapy $[29,30]$. We and others have reported that HNP-1 induces the production of IL-8 from airway epithelial cells $[11,16]$. We also have reported that $\alpha$-defensin levels in bronchoalveolar lavage fluid (BALF) in patients with diffuse panbronchiolitis were highly elevated compared with healthy subjects and correlated with IL-8 levels in BALF [31]. These results suggest that IL-8 synthesis in airway 
epithelial cells induced by HNP-1 contribute to unnecessary lung neutrophilic inflammation or sustain inflammation. Therefore, it is a considerable feature that plectasin does not induce IL-8 production from human airway epithelial cells.

The features of human defensins, which are limited stability, unknown toxicology and pharmacokinetics, induction of inflammatory cytokines, and their high cost, may be a detriment in clinical applications. Recently, surrogate agents of human defensins have been found from many kinds of organisms, including plants [32], insects [17], and fungi [18]. These defensin-like peptides, especially those derived from fungi, have a high degree of sequence and structural similarity to plectasin [18]. Perhaps the search for antimicrobial peptides similar to plectasin, produced by other fungi, insects, and plants, may contribute to the development and evolution of novel antimicrobial drugs in clinical applications. 


\section{Acknowledgments}

The authors thank Peptide Institute, Inc. for the reagents (plectasin and HNP-1) provided and Mr. Atsushi Yokoyama (Nagasaki University School of Medicine) for excellent technical assistance. This study was supported in part by Grants-in-Aid for Scientific Research [KAKENHI](c).

\section{References}

[1] M.E. Selsted and A.J. Ouellette, Mammalian defensins in the antimicrobial immune response, Nat. Immunol. 6 (2005) 551-7.

[2] M.M. Welling, P.S. Hiemstra, M.T. van den Barselaar, A. Paulusma-Annema, P.H. Nibbering, E.K. Pauwels, W. Calame, Antibacterial activity of human neutrophil defensins in experimental infections in mice is accompanied by increased leukocyte accumulation, J. Clin. Invest. 102 (1998) 1583-90.

[3] A. Kalita, I. Verma, G.K. Khuller, Role of human neutrophil peptide-1 as a possible adjunct to antituberculosis chemotherapy, J. Infect. Dis. 190 (2004) 1476-80.

[4] R.E. Hancock and H.G. Sahl, Antimicrobial and host-defense peptides as new anti-infective therapeutic strategies, Nat. Biotechnol. 24 (2006) 1551-7.

[5] A.K. Marr, W.J. Gooderham, R.E. Hancock, Antibacterial peptides for therapeutic use: obstacles and realistic outlook, Curr. Opin. Pharmacol. 6 (2006) 468-72. [6] D. Yang, A. Biragyn, L.W. Kwak, J.J. Oppenheim, Mammalian defensins in immunity: more than just microbicidal, Trends Immunol. 23 (2002) 291-6. 
[7] P.A. Raj and A.R. Dentino, Current status of defensins and their role in innate and adaptive immunity, FEMS Microbiol. Lett. 206 (2002) 9-18.

[8] D.M. Bowdish, D.J. Davidson, R.E. Hancock, A re-evaluation of the role of host defence peptides in mammalian immunity, Curr. Protein Pept. Sci. 6 (2005) 35-51.

[9] G. Maisetta, M. Di Luca, S. Esin, W. Florio, F.L. Brancatisano, D. Bottai, M. Campa, G. Batoni, Evaluation of the inhibitory effects of human serum components on bactericidal activity of human beta defensin 3, Peptides 29 (2008) 1-6.

[10] R.I. Lehrer, A.K. Lichtenstein, T. Ganz, Defensins: antimicrobial and cytotoxic peptides of mammalian cells, Annu. Rev. Immunol. 11 (1993) 105-28.

[11] N. Sakamoto, H. Mukae, T. Fujii, H. Ishii, S. Yoshioka, T. Kakugawa, K. Sugiyama, Y. Mizuta, J. Kadota, M. Nakazato, S. Kohno, Differential effects of alpha- and beta-defensin on cytokine production by cultured human bronchial epithelial cells, Am. J. Physiol. Lung Cell Mol. Physiol. 288 (2005) L508-13.

[12] S. Yoshioka, H. Mukae, H. Ishii, T. Kakugawa, H. Ishimoto, N. Sakamoto, T. Fujii, Y. Urata, T. Kondo, H. Kubota, K. Nagata, S. Kohno, Alpha-defensin enhances expression of HSP47 and collagen-1 in human lung fibroblasts, Life Sci. 80 (2007) $1839-45$.

[13] H. Zhang, G. Porro, N. Orzech, B. Mullen, M. Liu, A.S. Slutsky, Neutrophil defensins mediate acute inflammatory response and lung dysfunction in dose-related fashion, Am. J. Physiol. Lung Cell Mol. Physiol. 280 (2001) L947-54. 
[14] H. Mukae, H. Iiboshi, M. Nakazato, T. Hiratsuka, M. Tokojima, K. Abe, J. Ashitani, J. Kadota, S. Matsukura, S. Kohno, Raised plasma concentrations of alpha-defensins in patients with idiopathic pulmonary fibrosis, Thorax 57 (2002) 623-8.

[15] J. Ashitani, H. Mukae, Y. Arimura, A. Sano, M. Tokojima, M. Nakazato, High concentrations of alpha-defensins in plasma and bronchoalveolar lavage fluid of patients with acute respiratory distress syndrome, Life Sci. 75 (2004) 1123-34.

[16] S. Van Wetering, S.P. Mannesse-Lazeroms, J.H. Dijkman, P.S. Hiemstra, Effect of neutrophil serine proteinases and defensins on lung epithelial cells: modulation of cytotoxicity and IL-8 production, J. Leukoc. Biol. 62 (1997) 217-26.

[17] K. Thevissen, H.H. Kristensen, B.P. Thomma, B.P. Cammue, I.E. Francois, Therapeutic potential of antifungal plant and insect defensins, Drug Discov. Today 12 (2007) 966-71.

[18] S. Zhu, Discovery of six families of fungal defensin-like peptides provides insights into origin and evolution of the CSalphabeta defensins, Mol. Immunol. 45 (2008) 828-38.

[19] P.H. Mygind, R.L. Fischer, K.M. Schnorr, M.T. Hansen, C.P. Sonksen, S. Ludvigsen, D. Raventos, S. Buskov, B. Christensen, L. De Maria, O. Taboureau, D. Yaver, S.G. Elvig-Jorgensen, M.V. Sorensen, B.E. Christensen, S. Kjaerulff, N. Frimodt-Moller, R.I. Lehrer, M. Zasloff, H.H. Kristensen, Plectasin is a peptide antibiotic with therapeutic potential from a saprophytic fungus, Nature 437 (2005) 975-80. 
[20] The Clinical and Laboratory Standards Institute, Guideline M7-A6: Methods for dilution antimicrobial susceptibility tests for bacteria that grow aerobically. [21] Y. Nakajima, J. Ishibashi, F. Yukuhiro, A. Asaoka, D. Taylor, M. Yamakawa, Antibacterial activity and mechanism of action of tick defensin against Gram-positive bacteria, Biochim. Biophys. Acta. 1624 (2003) 125-30.

[22] J.E. Gabay, J.M. Heiple, Z.A. Cohn, C.F. Nathan, Subcellular location and properties of bactericidal factors from human neutrophils, J. Exp. Med. 164 (1986) 1407-21.

[23] M.J. Goldman, G.M. Anderson, E.D. Stolzenberg, U.P. Kari, M. Zasloff, J.M. Wilson, Human beta-defensin-1 is a salt-sensitive antibiotic in lung that is inactivated in cystic fibrosis, Cell 88 (1997) 553-60.

[24] B. Dickinson, Mueller Hinton II Broth (Cation-Adjusted), Difco/BBL Manual.

[25] H. Takemura, M. Kaku, S. Kohno, Y. Hirakata, H. Tanaka, R. Yoshida, K. Tomono, H. Koga, A. Wada, T. Hirayama, S. Kamihira, Evaluation of susceptibility of gram-positive and -negative bacteria to human defensins by using radial diffusion assay, Antimicrob. Agents Chemother. 40 (1996) 2280-4.

[26] S.S. Harwig, T. Ganz, R.I. Lehrer, Neutrophil defensins: purification, characterization, and antimicrobial testing, Methods Enzymol. 236 (1994) 160-72. [27] J. Aarbiou, M. Ertmann, S. van Wetering, P. van Noort, D. Rook, K.F. Rabe, S.V. Litvinov, J.H. van Krieken, W.I. de Boer, P.S. Hiemstra, Human neutrophil defensins induce lung epithelial cell proliferation in vitro, J. Leukoc. Biol. 72 (2002) 167-74. 
[28] M. Baggiolini, A. Walz, S.L. Kunkel, Neutrophil-activating peptide-1/interleukin 8, a novel cytokine that activates neutrophils, J. Clin. Invest. 84 (1989) 1045-9.

[29] J. Kadota, O. Sakito, S. Kohno, H. Sawa, H. Mukae, H. Oda, K. Kawakami, K.

Fukushima, K. Hiratani, K. Hara, A mechanism of erythromycin treatment in patients with diffuse panbronchiolitis, Am. Rev. Respir. Dis. 147 (1993) 153-9.

[30] S. Mattoli, V.L. Mattoso, M. Soloperto, L. Allegra, A. Fasoli, Cellular and biochemical characteristics of bronchoalveolar lavage fluid in symptomatic nonallergic asthma, J. Allergy Clin. Immunol. 87 (1991) 794-802.

[31] J. Ashitani, H. Mukae, M. Nakazato, T. Ihi, H. Mashimoto, J. Kadota, S. Kohno, S. Matsukura, Elevated concentrations of defensins in bronchoalveolar lavage fluid in diffuse panbronchiolitis, Eur. Respir. J. 11 (1998) 104-11.

[32] F.T. Lay and M.A. Anderson, Defensins--components of the innate immune system in plants, Curr. Protein Pept. Sci. 6 (2005) 85-101. 


\section{Figure legends}

Fig. 1. Antibacterial activity of plectasin in the absence or presence of human serum.

Representative result of the minimal inhibitory concentration of plectasin against

penicillin-susceptible S. pneumonia (PSSP) and penicillin-resistant S. pneumonia (PRSP). PSSP and PRSP strains were ATCC 49619 and a clinical isolate from Nagasaki University, respectively. Sterile controls (far right lane) were all negative.

Fig. 2. Cytotoxicity of plectasin and HNP-1 on cytotoxicity for A549 cells (A), NHBE (B) and NHLF (C).

Cells were separately incubated for $24 \mathrm{~h}$ with $0 \mu \mathrm{g} / \mathrm{ml}$ (control) to $50 \mu \mathrm{g} / \mathrm{ml}$ of plectasin or HNP-1. Cytotoxic effects at different concentrations of plectasin and HNP-1 were measured by AlamarBlue assay. The levels of reduced cell viability were compared with those of control. The resulting ratio is shown as the percentage change from control values. Values are means \pm SEM of three experiments performed in duplicate. ${ }^{*} P<0.01$ compared with control. Round marker $(\mathbf{O})$ and solid line are plectasin. Square marker $(\square)$ and dotted line are HNP-1.

Fig. 3. Effect of plectasin on IL-8 production in human bronchial epithelial cells.

Gene expression of IL-8 in A549 cells stimulated with medium alone (control) or 1 $50 \mu \mathrm{g} / \mathrm{ml}$ of plectasin or HNP-1 for $3 \mathrm{~h}$ using quantitative real-time PCR method (A). 
All quantifications of gene expression were normalized to the housekeeping gene $\beta$-actin. The data are presented as the ratio between the target gene expression and the gene expression in unstimulated conditions. Protein production of IL-8 in A549 cells stimulated with medium alone or $1-50 \mu \mathrm{g} / \mathrm{ml}$ of plectasin or HNP-1 for $24 \mathrm{~h}$ by ELISA (B). Values are mean \pm SD of three experiments. ${ }^{*} P<0.01$ compared with control. 
Table 1. Antibacterial activities of plectasin

The minimal inhibitory concentration (MIC) was determined as described in the Methods section. PSSP, penicillin-susceptible S. pneumoniae; PRSP, penicillin-resistant S. pneumoniae; MSSA, methicillin-susceptible S. aureus; MRSA, methicillin-resistant $S$. aureus; MS-CNS, methicillin-susceptible coagulase-negative Staphylococci; MR-CNS, methicillin-resistant coagulase-negative Staphylococci. 


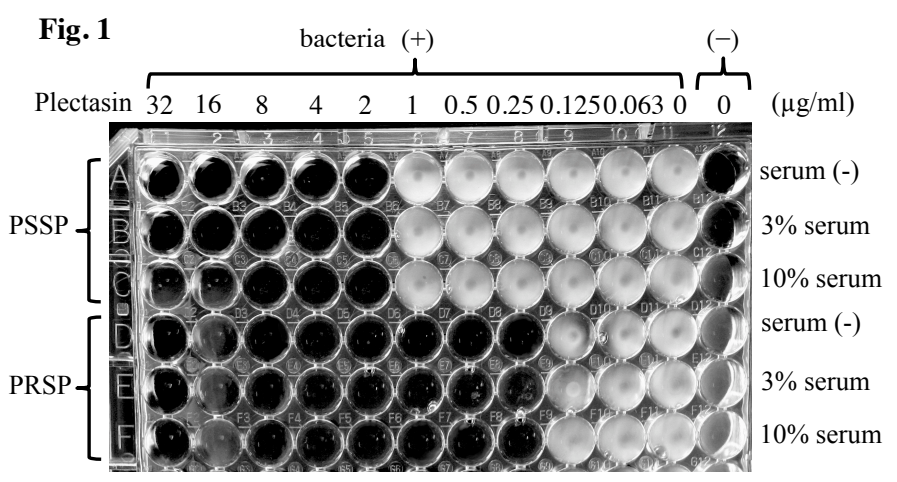

Fig. 3(A)

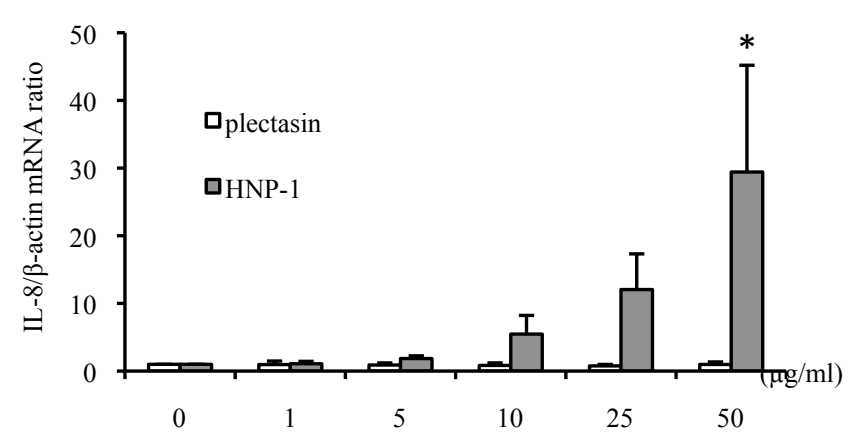

Fig. 3(B)

Fig. 2(A)
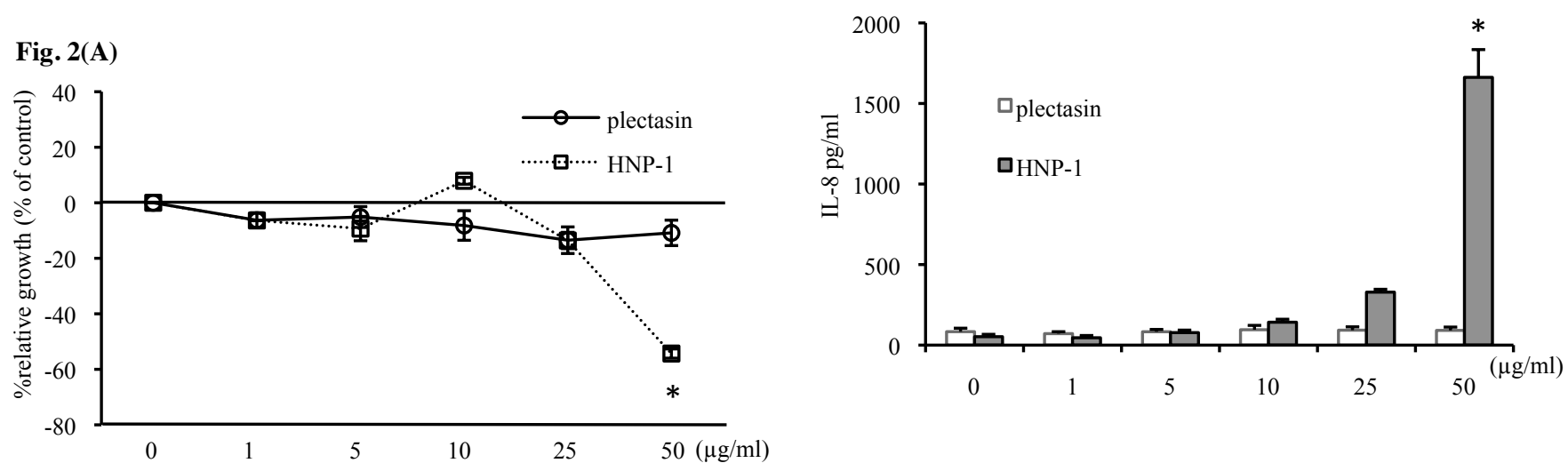

Fig. 2(B)

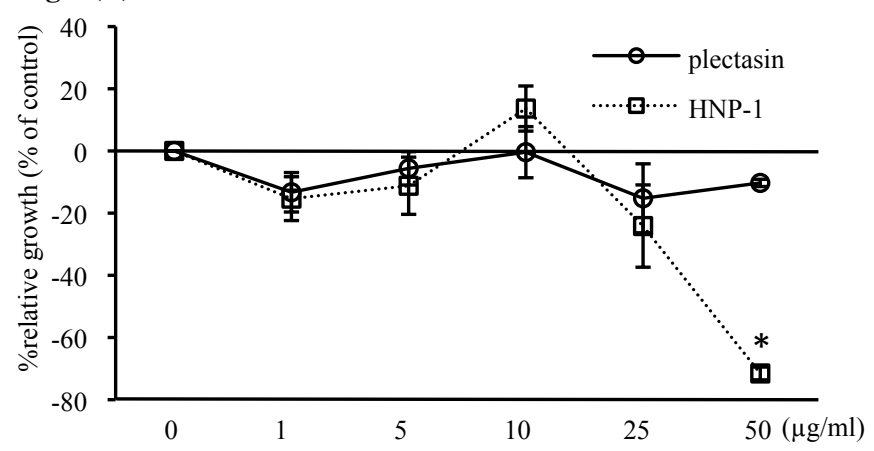

Fig. 2(C)

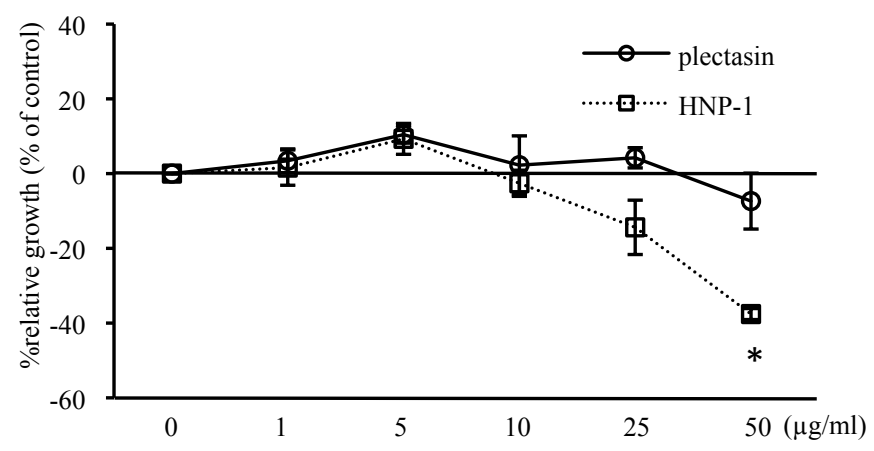


Table 1

Bacterial No. Minimum inhibitory concentration $(\mu \mathrm{g} / \mathrm{ml})$

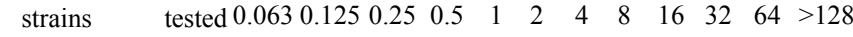

\begin{tabular}{lccccccccccccc}
\hline PSSP & 8 & - & 2 & 1 & 3 & - & 2 & - & - & - & - & - & - \\
$P R S P$ & 13 & 3 & - & 4 & 4 & 2 & - & - & - & - & - & - & - \\
$M S S A$ & 11 & - & - & - & - & - & - & - & 2 & 7 & 1 & 1 & - \\
MRSA & 11 & - & - & - & - & - & - & - & - & 8 & 3 & - & - \\
MS-CNS & 10 & - & - & - & 1 & 1 & 1 & 2 & 2 & 3 & - & - & - \\
MR-CNS & 9 & - & - & - & - & - & - & 1 & 1 & 2 & 1 & 2 & 9 \\
H. influenzae & 10 & - & - & - & - & - & - & - & - & - & - & - & 10 \\
P. aeruginosa & 2 & - & - & - & - & - & - & - & - & - & - & - & 2 \\
\hline
\end{tabular}

